\title{
Knowledge and Attitudes towards Acetaminophen Use in Saudi Arabia
}

\author{
Ziyad Alrabiah 1,*,\#, Abdulrahman Alwhaibi ${ }^{1, \#}$, Afraa Alzoubi ${ }^{2}$, Sary Alsanea ${ }^{2}$, Abdulaziz Alhossan $^{1}$ \\ 'Department of Clinical Pharmacy, College of Pharmacy, King Saud University, Riyadh, SAUDI ARABIA. \\ 2Department of Pharmacology and Toxicology, College of Pharmacy, King Saud University, Riyadh, SAUDI ARABIA. \\ \#This Authors have Contributed Equally
}

\begin{abstract}
Background: Despite the common use of acetaminophen and its safety profile, cases of acetaminophen-induced hepatic toxicities have been reported due to unintentional duplication that mostly results from the public significant lack of knowledge. This research aims to assess the public awareness towards the safe use of acetaminophen in Saudi Arabia. Methods: A cross-sectional study that targeted the adults in Saudi Arabia that was carried out using self-administered questionnaire. The data obtained included sociodemographic characteristics, the pattern of use, the attitude, as well as the knowledge of the general public towards acetaminophen. Results: Data presented in this study showed that a significant majority of the respondents $(84.11 \%)$ used acetaminophen without their physician's prescription as needed, (66\%) denied the development of side effects after using acetaminophen. In terms of the participants' knowledge and awareness towards the usage of acetaminophen and its safety, a pronounced proportion of the respondents $(53.65 \%)$ incorrectly identified the maximum daily dose of acetaminophen and only $(16.2 \%)$ could. A significant minority of the participants $(27 \%)$ admitted relying on their own knowledge as the primary source of
\end{abstract}

information. Among the participants (54.69\%) denied receiving education on acetaminophen from health care professionals. A marked distinction was observed between the respondents with higher educational level as well as younger individuals regarding the identification of the maximum daily dose $(p=0.0034)$ and $(p=0.039)$, respectively. Conclusion: There is a concerning inadequacy of the public awareness about the appropriate use of acetaminophen.

Key words: Acetaminophen, Knowledge, Non-prescription medications, Over dosage, Paracetamol.

\section{Correspondence}

Dr. Ziyad Alrabiah,

Assistant Professor, Department of Clinical Pharmacy, College of Pharmacy, King Saud University, P. O. Box 2457, Riyadh 11451, SAUDI ARABIA.

Email id: zalrabiah@ksu.edu.sa

DOI: 10.5530/jyp.2021.13.101

\section{INTRODUCTION}

Acetaminophen (also known as Paracetamol) is one of the most commonly used non-prescription medications worldwide. ${ }^{1}$ It is mainly utilized for its analgesic and antipyretic effects, either alone or as an ingredient in a myriad of prescription preparations ${ }^{2}$ including but not limited to narcotics and cough syrups. ${ }^{1}$ Acetaminophen has a welldocumented safety profile when consumed in the recommended doses that must not exceed $4000 \mathrm{mg}$ per day. ${ }^{3}$ However, cases of hepatotoxicity and acute liver failure (ALF) with subsequent liver transplantations have been reported with acetaminophen overdosage. ${ }^{4}$ Approximately, $50 \%$ of acetaminophen-induced hepatotoxicity was attributed to the unintentional ingestion of repeated doses without adhering to the maximum daily dose, or the accidental consumption of various compounds containing acetaminophen. ${ }^{2}$ From our perspective, this clearly highlights the significant lack of knowledge in the public domain ${ }^{5}$ with respect to the drug consumption and its availability in the market. In other words, since acetaminophen can be purchased from stores other than pharmacies, such as supermarkets or grocery stores, patients might not receive sufficient information on its proper use, which could potentially result into ALF. ${ }^{1,6}$

Multiple recent cross-sectional studies that were performed in Saudi Arabia reported that there is a pronounced lack of knowledge in the public domain about the usage of analgesics and their health hazards. ${ }^{6-8}$ Among these; two studies ${ }^{6,7}$ found that acetaminophen is the most excessively used analgesic among the Saudi population. Therefore, it is essential that patients maintain adequate knowledge about the plausible risks of acetaminophen-related toxicities in order to avoid any unwanted consequences. Similar studies were conducted in the United States to evaluate the public knowledge of the use of acetaminophen, have reported that the American population had insufficient and scarce information about its proper use. ${ }^{3,59}$ To the best of our knowledge, published data regarding the perception and attitudes of the local population towards the usage and the conceivable dangers of acetaminophen, are still unsatisfactory. ${ }^{6-8}$ Performing such studies is necessary to investigate the quality of patient education and demonstrate the crucial role of health care professionals, particularly pharmacists and physicians, in providing high levels of patient medical vigilance to protect them from detrimentally unexpected medical consequences. The primary purpose of this study is to estimate the knowledge and attitudes of the general population towards the use of acetaminophen in Saudi Arabia.

\section{METHODS}

A cross-sectional survey to evaluate the public knowledge of the uses and health risks of acetaminophen was conducted in Riyadh, Saudi Arabia. This study was ethically approved by King Saud University's institutional review board before data collection. The participants received the questionnaire through social media.

The questionnaire was developed by an extensive literature review and it was validated by senior researchers. It comprised two parts; the first part is composed of demographic data which include: gender, age, educational level, career, and the presence of chronic diseases. Whereas, the second part was focused on the respondents' awareness towards 
Alrabiah, et al:: Knowledge and Attitudes towards Acetaminophen use

the usage of acetaminophen that was assessed utilizing 19 multiplechoice questions which pertain to; "the pattern of acetaminophen use, its daily consumption, duration, and the frequency of its use during the past 6 months, as well as, the maximum daily dose of acetaminophen, its recognition as an ingredient in multiple pharmaceutical products, the source of education regarding its use, the side effects experienced due to its use, and the medical condition that necessitates their use of acetaminophen."

\section{Statistical Analysis}

The data were analyzed using SPSS Version 22 for Windows for analysis. Descriptive statistics including percentages and frequency distribution were calculated for each variable. Chi-square test was utilized to compare study outcomes for categorical data. A $p<0.05$ was interpreted as statistically significant.

\section{RESULTS}

A total of 384 participants completed the survey with a relatively marked female predominance $(64.06 \%)$. The participants were categorized based on their age into 6 subgroups; more than half of them ( $n=222,57.81 \%)$ belonged to the age subgroup (18-25 years old), and living in large cities. The educational level of the participants was also analyzed showing the highest proportion with a bachelor's degree $(58.33 \%)$. one third of the participants $(23.70 \%)$ reported having chronic diseases; among which diabetes was the most clearly specified illness (17.58\%) of the overall cases. Most of the participants (84.11\%) reported using acetaminophen as needed without their physicians' prescriptions. Whereas, a reasonable proportion of them $(23 \%)$ indicated that they used it at the time of pain. Around (37\%) of the users could not recall the number of times they have used it during the past six months, and to a lesser extinct (30.73\%) reported using it more than three times per that period. Of the respondents, $(73 \%)$ indicated that headache was the chief complaint behind acetaminophen administration, followed by Cold and flu (35\%), and fever (26\%). They were also asked about the possible side effects they might have experienced after using it, and (66\%) did not suffer from any, while Nausea and vomiting were reported by (18\%), Stomach ulcer by (13\%) and Dizziness by (11\%).

The users were also queried to determine the dosage of the last time they received acetaminophen, and (50.78\%) admitted consuming only one pill a day, and a markedly high percentage $(73.96 \%)$ declared using acetaminophen for less than a week.

Interestingly, Riyadh residents were significantly higher than other regions' participants (57\%) in using acetaminophen without doctor's prescription $(p=0.0024)$. Younger individuals particularly those in the age subgroup (18-25) were markedly more than senior participants in using acetaminophen by more than three times during the last six months $(p=0.0101)$ (Table 1$)$.

When the users were asked to determine the formulations that might contain acetaminophen as the main active ingredient, eighty six percent of them identified certain brands such as Panadol ${ }^{\circ}$, followed by Fevadol ${ }^{\circ}$ (72\%), Adol $^{\circledR}(68 \%)$, Cetamol $^{\circledR}(36 \%)$, and Flutab ${ }^{\oplus}(30 \%)$. The respondents were also asked to indicate the type of medications that might contain acetaminophen as an ingredient, and (85\%), (63\%), (30\%), and (24\%) of them answered pain relivers, fever, cold/allergy products and sleeping aids, respectively.

Unexpectedly, more than half of the participants ( $n=206,53.65 \%)$ did not know the maximum daily dose of acetaminophen, and only (16.2\%) identified $4 \mathrm{~g}$ as the maximum daily dosage. A statistically significant difference was observed between males and females, as a larger number of males correctly identified the maximum daily dosage than females ( $p=0.0005$ ) (Table 2 ). Comparably, younger users exhibited more knowledge about the maximum dosage than senior participants $(p=0.039)$. Educational level markedly impacted participants awareness on the maximum daily dose particularly those who had a bachelor's degree ( $p=0.0034$ ). The public knowledge regarding the side effects of the chronic use of acetaminophen was also analyzed where (84\%) believed that its chronic use can lead to various adverse effects, while (16\%) of them denied that.

A relatively large number of the participants $(n=236,61.46 \%)$ decided taking acetaminophen without any recommendations from health care professionals the last time they needed to use it, and only ( $n=54,14.06 \%)$ did use it based on their physicians' advice. Forty three percent of the users indicated that they would stop treatment in case they experienced any adverse effects after ingesting acetaminophen, while (26.3\%) of them would visit their physicians to consult them on how to control the side effects. The respondents were asked about the source from which they receive their information about acetaminophen. Astonishingly, $(n=104$, $27.08 \%)$ reported mainly depending on their personal knowledge. Whereas, $(n=96,25.26 \%)$ utilized the internet to obtain information about the medication, and only $(n=54,14.06 \%)$ asked their pharmacists. The results showed that $(n=147,38.28 \%)$ of the study population would not purchase acetaminophen from a place other than the pharmacy because of the plausibility of inappropriate storing conditions, and $(n=99,25.78 \%)$ users admitted that they would acquire the medication from the market. The participants were also asked if they had ever received education on acetaminophen from health care professionals; surprisingly, $(n=210,54.69 \%)$ denied receiving any education, while $(n=174,45.31 \%)$ reported the contrary, of which $(n=102,59 \%)$ were provided education by pharmacists, and $(n=63,36 \%)$ by doctors.

Participants with chronic diseases were queried if they would contact their physicians or pharmacists before the use of acetaminophen, and a relatively large proportion of them $(62.80 \%)$ conceded that they do not consult their physicians, prior the use of acetaminophen. Similarly, (34.3\%) did not discuss that with their pharmacists either.

The association between the participants' gender and their responses regarding the likelihood of purchasing acetaminophen from places other than the pharmacy was quite pronounced $(p=0.0062)$, the regions of the respondents similarly affected their answers $(p=0.008)$ (Table 3$)$.

\section{DISCUSSION}

The recurrent usage of acetaminophen among the Saudi population entails the augmentation of patient education to limit the frequent occurrences of its harmful effects, and accidental toxicities, particularly self-medication which has become a common public phenomenon. ${ }^{10}$

Multiple studies worldwide ${ }^{11,12}$ and in Saudi Arabia ${ }^{8,13}$ have demonstrated that analgesics, particularly acetaminophen, represent the most requested drug in the self-medication category. These observations agree with the findings of our study where $(84.11 \%)$ of the respondents admitted using acetaminophen without doctors' prescription as required. This could be attributed to a myriad of reasons; acetaminophen is potentially used due to its effectiveness in treating various ailments as observed in the present study; headache (73\%), cold and flu (35\%) and fever (26\%). Another possible explanation for the extensive use of this medication is its relative safety among all ages in the recommended doses, as noted in the current study, where a remarkably high proportion of the users $(66 \%)$ denied experiencing adverse effects upon its administration. Despite that, the most concerning, is the fact that, acetaminophen overdose causes lifethreatening cases of liver failure. This remains asymptomatic during the first few hours and can be detected by blood tests, which would result, if left untreated, in hospital admissions and plausible deaths. ${ }^{14}$ 
Table 1: The comparison of responses between the different age groups.

\begin{tabular}{|c|c|c|c|c|c|c|c|c|}
\hline Parameter & Category & $\begin{array}{l}18-25 \\
\text { years } \\
\text { old }\end{array}$ & $\begin{array}{l}26-35 \\
\text { years } \\
\text { old }\end{array}$ & $\begin{array}{l}36-45 \\
\text { years } \\
\text { old }\end{array}$ & $\begin{array}{l}46-60 \\
\text { years } \\
\text { old }\end{array}$ & $\begin{array}{l}\text { Less } \\
\text { than } 18 \\
\text { years } \\
\text { old }\end{array}$ & $\begin{array}{l}\text { Older } \\
\text { than } 60 \\
\text { years } \\
\text { old }\end{array}$ & p-value \\
\hline \multirow{6}{*}{$\begin{array}{l}\text { The person who recommended the } \\
\text { usage of acetaminophen }\end{array}$} & A friend of mine & 6 & 1 & 0 & 0 & 6 & 0 & \multirow{6}{*}{0.0215} \\
\hline & My pharmacist & 12 & 6 & 4 & 2 & 4 & 0 & \\
\hline & My physician & 25 & 8 & 11 & 4 & 6 & 0 & \\
\hline & My physician in a similar situation in the past & 7 & 2 & 0 & 1 & 2 & 0 & \\
\hline & No one, it was my own decision & 145 & 27 & 22 & 17 & 22 & 3 & \\
\hline & One of my close relatives & 27 & 0 & 1 & 0 & 13 & 0 & \\
\hline \multirow[t]{6}{*}{$\begin{array}{l}\text { The attitudes regarding the side } \\
\text { effects of acetaminophen }\end{array}$} & $\begin{array}{l}\text { Continue Paracetamol use and associate } \\
\text { another treatment to treat symptoms }\end{array}$ & 6 & 0 & 1 & 0 & 0 & 0 & \multirow{6}{*}{0.9998} \\
\hline & I go to the hospital & 42 & 6 & 7 & 5 & 13 & 1 & \\
\hline & Reduce dose & 10 & 3 & 1 & 1 & 2 & & \\
\hline & Stop treatment & 89 & 21 & 18 & 12 & 24 & 2 & \\
\hline & Switch to another treatment & 14 & 2 & 0 & 1 & 2 & 0 & \\
\hline & Visit doctor & 61 & 12 & 11 & 5 & 12 & 0 & \\
\hline \multirow[t]{8}{*}{ The source of knowledge } & Advertisements on TV/Internet & 2 & 1 & 1 & 0 & 2 & 0 & \multirow{8}{*}{0.0005} \\
\hline & Internet (webpages) & 52 & 15 & 13 & 6 & 11 & 0 & \\
\hline & My friends and relatives & 14 & 1 & 0 & 0 & 10 & 0 & \\
\hline & My personal knowledge & 73 & 7 & 8 & 5 & 11 & 0 & \\
\hline & My pharmacist & 36 & 7 & 3 & 4 & 4 & & \\
\hline & My physician & 9 & 2 & 4 & 4 & 3 & 1 & \\
\hline & Nobody & 28 & 7 & 5 & 3 & 9 & 2 & \\
\hline & Previous prescription & 8 & 4 & 4 & 2 & 3 & 0 & \\
\hline \multirow{5}{*}{$\begin{array}{l}\text { Whether the participants purchase } \\
\text { acetaminophen from channels other } \\
\text { than the pharmacy }\end{array}$} & $\begin{array}{l}\text { In some cases, if I have already bought it from } \\
\text { the pharmacy }\end{array}$ & 19 & 1 & 1 & 1 & 0 & 0 & \multirow{5}{*}{0.1776} \\
\hline & No, since I would like to have expert advice & 15 & 3 & 4 & 5 & 6 & 0 & \\
\hline & $\begin{array}{l}\text { No, since I'm not sure if they have been stored } \\
\text { in the appropriate way }\end{array}$ & 76 & 16 & 20 & 11 & 24 & & \\
\hline & Yes & 62 & 12 & 7 & 4 & 11 & 3 & \\
\hline & Yes, if I was in a hurry & 50 & 12 & 6 & 3 & 12 & 0 & \\
\hline \multirow{5}{*}{$\begin{array}{l}\text { The frequency of Paracetamol use } \\
\text { (without doctor's prescription) }\end{array}$} & Every day & 7 & 2 & 1 & 1 & 3 & 0 & \multirow{5}{*}{0.9930} \\
\hline & It depends on my demands (As needed) & 184 & 33 & 35 & 21 & 47 & 3 & \\
\hline & Once per month (Monthly) & 8 & 2 & 1 & 0 & 0 & 0 & \\
\hline & Once per week (Weekly) & 8 & 3 & 0 & 2 & 3 & 0 & \\
\hline & Two times per week & 15 & 4 & 1 & 0 & 0 & 0 & \\
\hline \multirow{5}{*}{$\begin{array}{l}\text { The frequency of acetaminophen } \\
\text { usage during the last six months }\end{array}$} & $>3$ times & 71 & 19 & 10 & 6 & 10 & 2 & \multirow{5}{*}{0.0101} \\
\hline & 3 times & 37 & 2 & 5 & 2 & 3 & & \\
\hline & Do not remember & 75 & 15 & 17 & 8 & 27 & & \\
\hline & Once & 14 & 5 & 1 & 7 & 7 & 1 & \\
\hline & Twice & 25 & 3 & 5 & 1 & 6 & & \\
\hline
\end{tabular}


Table 2: The influence of the sociodemographic factors on the knowledge of the maximum daily dosage.

\begin{tabular}{|c|c|c|c|c|c|c|c|c|}
\hline \multirow[t]{2}{*}{ Parameter } & \multirow[t]{2}{*}{ Category } & \multicolumn{6}{|c|}{ The maximum daily dose } & \multirow[t]{2}{*}{ P-value } \\
\hline & & $\begin{array}{l}\text { I don't } \\
\text { know }\end{array}$ & $1 \mathrm{~g}$ & $3 g$ & $4 g$ & $5 g$ & $500 \mathrm{mg}$ & \\
\hline \multirow[t]{2}{*}{ Gender } & Male & 62 & 4 & 17 & 36 & 9 & 10 & \multirow{2}{*}{0.0005} \\
\hline & Female & 144 & 26 & 12 & 26 & 2 & 36 & \\
\hline \multirow[t]{6}{*}{ Age } & $18-25$ years old & 95 & 20 & 22 & 51 & 10 & 24 & \multirow{6}{*}{0.0398} \\
\hline & Less than 18 years old & 39 & 2 & 3 & 2 & 1 & 6 & \\
\hline & 26-35 years old & 25 & 4 & 1 & 7 & 0 & 7 & \\
\hline & $36-45$ years old & 27 & 3 & 2 & 2 & 0 & 4 & \\
\hline & $46-60$ years old & 17 & 1 & 1 & 0 & 0 & 5 & \\
\hline & Older than 60 years old & 3 & 0 & 0 & 0 & 0 & 0 & \\
\hline \multirow[t]{2}{*}{ Nationality } & Saudi & 194 & 29 & 28 & 61 & 11 & 44 & \multirow{2}{*}{0.808} \\
\hline & Non-Saudi & 12 & 1 & 1 & 1 & 0 & 2 & \\
\hline \multirow[t]{5}{*}{ Educational level } & Bachelor's degree & 98 & 23 & 22 & 51 & 5 & 25 & \multirow{5}{*}{0.0034} \\
\hline & High school certificate & 78 & 4 & 6 & 6 & 5 & 19 & \\
\hline & Diploma certificate & 10 & 1 & 1 & 1 & 0 & 1 & \\
\hline & Primary/Elementary & 13 & 0 & 0 & 1 & 0 & 0 & \\
\hline & Postgraduate or $\mathrm{PhD}$ & 7 & 2 & 0 & 3 & 1 & 1 & \\
\hline \multirow[t]{4}{*}{ Career } & Student & 127 & 19 & 23 & 49 & 8 & 25 & \multirow{4}{*}{0.401} \\
\hline & Employed & 53 & 9 & 3 & 10 & 3 & 12 & \\
\hline & Unemployed & 23 & 2 & 2 & 3 & 0 & 7 & \\
\hline & Retired & 3 & 0 & 1 & 0 & 0 & 2 & \\
\hline \multirow[t]{2}{*}{ Chronic disease } & No, I don't have any chronic disease & 157 & 23 & 22 & 50 & 6 & 35 & \multirow{2}{*}{0.6} \\
\hline & Yes & 49 & 7 & 7 & 12 & 5 & 11 & \\
\hline
\end{tabular}

Several factors can result in those unforeseen consequences; one of which is the inadequate knowledge among patients, which we showed in this study, and was notably demonstrated by two previous studies. ${ }^{6,7} \mathrm{It}$ was observed that only (16.2\%) of the participants were able to correctly identify $4 \mathrm{~g}$ as the maximum daily dose of acetaminophen. This was significantly correlated to the educational level of the respondents as well as, their age. Comparable findings were reported in two American studies; Herndon et al. ${ }^{9}$ and Hornsby et al. ${ }^{3}$ which found that less than $25 \%$ and only one third of the participants were able to determine the appropriate maximum daily dose, respectively. Similarly, a pronounced proportion of the participants could not recognize acetaminophencontaining products which might lead to unintentional duplication and consequential toxicities. Furthermore, it was perceived that $(27 \%)$ of the users relied on their personal knowledge as the primary source of information regarding the use of acetaminophen, which has been reported to reach (45.1\%) by Babakor et al. ${ }^{6}$

Another critical factor is health care professionals, as they can prevent acetaminophen-related health risks by counselling their patients and by providing sufficient education on its appropriate usage upon prescribing or dispensing. Data presented here, showed that (54.69\%) of the subjects had never received health education on the proper use of acetaminophen. In general, this agrees with those investigated by Stumpf et al. ${ }^{5}$ (53.85. However, although (59.8\%) of the participants of Babakor et al. ${ }^{6}$ declared that pharmacists did not provide them with information related to acetaminophen utilization, the current study showed that a comparable number of users (45.31\%) admitted otherwise.

Finally, and possibly considered a barrier to close medical observation is the availability of acetaminophen in other nonmedical channels as reported in our study that $(47.39 \%)$ of the consumers might purchase acetaminophen from the market.

The study involves a few limitations, since it utilized a self-administered questionnaire, this might lead to desirability bias. It might contain recall bias; particularly in questions that involved the respondents' attitudes during the past six months. The study also had a female predominance and the majority of the participants were residents of Riyadh city.

\section{CONCLUSION}

Despite the excessive use of acetaminophen in Saudi Arabia, there is a concerning deficiency in the public knowledge about its appropriate use. Although educated individuals demonstrated a higher level of 


\section{Table 3: The comparison of responses between the two genders.}

\begin{tabular}{|c|c|c|c|c|}
\hline Parameter & Category & Male & Female & P-value \\
\hline \multirow{6}{*}{$\begin{array}{l}\text { The person who recommended the } \\
\text { usage of acetaminophen }\end{array}$} & A friend of mine & 38 & 39 & \multirow{6}{*}{0.0013} \\
\hline & My pharmacist & 51 & 144 & \\
\hline & My physician & 3 & 4 & \\
\hline & My physician in a similar situation in the past & 5 & 13 & \\
\hline & No one, it was my own decision & 6 & 9 & \\
\hline & One of my close relatives & 35 & 37 & \\
\hline \multirow{6}{*}{$\begin{array}{l}\text { The attitudes regarding the side effects } \\
\text { of acetaminophen }\end{array}$} & Continue Paracetamol use and associate another treatment to treat symptoms & 2 & 5 & \multirow{6}{*}{0.7113} \\
\hline & I go to the hospital & 25 & 49 & \\
\hline & Reduce dose & 6 & 11 & \\
\hline & Stop treatment & 57 & 109 & \\
\hline & Switch to another treatment & 10 & 9 & \\
\hline & Visit doctor & 38 & 63 & \\
\hline \multirow[t]{8}{*}{ The source of knowledge } & Advertisements on TV/Internet & 2 & 4 & \multirow{8}{*}{0.0032} \\
\hline & Internet (webpages) & 21 & 76 & \\
\hline & My friends and relatives & 13 & 12 & \\
\hline & My personal knowledge & 46 & 58 & \\
\hline & My pharmacist & 26 & 28 & \\
\hline & My physician & 5 & 18 & \\
\hline & Nobody & 20 & 34 & \\
\hline & Previous prescription & 5 & 16 & \\
\hline \multirow{5}{*}{$\begin{array}{l}\text { Whether the participants purchase } \\
\text { acetaminophen from channels other } \\
\text { than the pharmacy }\end{array}$} & In some cases, if I have already bought it from the pharmacy & 5 & 17 & \multirow{5}{*}{0.0062} \\
\hline & No, since I would like to have expert advice & 8 & 25 & \\
\hline & No, since I'm not sure if they have been stored in the appropriate way & 43 & 104 & \\
\hline & Yes & 48 & 51 & \\
\hline & Yes, if I was in a hurry & 34 & 49 & \\
\hline \multirow{5}{*}{$\begin{array}{l}\text { The frequency of acetaminophen use } \\
\text { (without doctor's prescription) }\end{array}$} & Every day & 5 & 9 & \multirow{5}{*}{0.3623} \\
\hline & It depends on my demands (As needed) & 122 & 201 & \\
\hline & Once per month (Monthly) & 2 & 9 & \\
\hline & Once per week (Weekly) & 5 & 11 & \\
\hline & Two times per week & 4 & 16 & \\
\hline \multirow{6}{*}{$\begin{array}{l}\text { The most recent consumed dosage of } \\
\text { acetaminophen }\end{array}$} & $2-3$ pills per day & 39 & 38 & \multirow{6}{*}{0.0013} \\
\hline & One pill & 144 & 51 & \\
\hline & One pill every day for 3-4 days & 4 & 3 & \\
\hline & One pill every day for a week & 13 & 5 & \\
\hline & Two pills every $4 \mathrm{hr}$ & 9 & 6 & \\
\hline & Two pills every $6 \mathrm{hr}$ & 37 & 35 & \\
\hline
\end{tabular}


awareness, there was a remarkable lack of information among the rest of the population about acetaminophen. Thus, structured educational measures are highly required to raise awareness, and warrant that patients are properly counselled about the safety profile of acetaminophen, and its permitted daily dose. It is also recommended to introduce methods that would assist patients in identifying acetaminophen in the combination formulations to prevent potential toxicities.

\section{ACKNOWLEDGEMENT}

The authors extend their appreciation to the Deanship of Scientific Research at King Saud University for this work through research no. RG-1441-455.

\section{CONFLICT OF INTEREST}

The authors declare no conflict of interest regarding the publication of this article.

\section{REFERENCES}

1. Mitchell RA, Rathi S, Dahiya M, Zhu J, Hussaini T, Yoshida EM. Public awareness of acetaminophen and risks of drug induced liver injury: Results of a large outpatient clinic survey. PLOS ONE. 2020;15(3):e0229070. doi: 10.1371/journal. pone.0229070, PMID 32130228

2. Stumpf JL, Liao AC, Nguyen S, Skyles AJ, Alaniz C. Knowledge of appropriate acetaminophen use: A survey of college-age women. J Am Pharm Assoc (2003). 2018;58(1):51-5. doi: 10.1016/j.japh.2017.09.002, PMID 29079404.

3. Hornsby LB, Whitley HP, Hester EK, Thompson M, Donaldson A. Survey of patient knowledge related to acetaminophen recognition, dosing, and toxicity. J Am Pharm Assoc (2003). 2010;50(4):485-9. doi: 10.1331/JAPhA.2010.08175, PMID 20621866.
4. Ali I, Khan AU, Khan J, Kaleem WA, Alam F, Khan TM. Survey of hospital pharmacists' knowledge regarding acetaminophen dosing, toxicity, product recognition and counselling practices. J Pharm Health Serv Res. 2017;8(1):39-43. doi: 10.1111/jphs.12148.

5. Stumpf JL, Skyles AJ, Alaniz C, Erickson SR. Knowledge of appropriate acetaminophen doses and potential toxicities in an adult clinic population. J Am Pharm Assoc (2003). 2007;47(1):35-41. doi: 10.1331/1544-3191.47.1.35.stumpf, PMID 17338473.

6. Babakor SD, Al Ghamdi MM. Prevalence and Determinants of Over-the-Counter analgesics Usage among Patients attending Primary Health Care Centers in Jeddah, Saudi Arabia. JYP. 2018;10(1):91-7. doi: 10.5530/jyp.2018.10.21.

7. Karami N, Altebainawi A, Alfarki S, Aldossari N, Asiri A, Aldahan M, et al. Knowledge and attitude of analgesics use among Saudi population: A cross-sectional study. Int J Med Sci Public Health. 2018. doi: 10.5455/ ijmsph.2018.0721125122017.

8. Qahl A, Albedaiwi Y, Faqihi A, Arishi N, Zarban Y, Hakeem F. Knowledge and attitude of analgesics usage among the Saudi population. IJMDC. 2020;4:318-24. doi: 10.24911/IJMDC.51-1574659696.

9. Herndon CM, Dankenbring DM. Patient perception and knowledge of acetaminophen in a large family medicine service. J Pain Palliat Care Pharmacother. 2014;28(2):109-16. doi: 10.3109/15360288.2014.908993, PMID 24813653.

10. Alghanim SA. Self-medication practice among patients in a public health care system. East Mediterr Health J. 2011;17(5):409-16. doi: 10.26719/2011.17.5.409 PMID 21796954

11. Carrasco-Garrido P, De Andrés AL, Barrera VH, Jiménez-Trujillo I, Fernandez-delas-Peñas $C$, Palacios-Ceña $D$, et al. Predictive factors of self-medicated analgesic use in Spanish adults: A cross-sectional national study. BMC Pharmacol Toxicol. 2014;15(1):36. doi: 10.1186/2050-6511-15-36, PMID 25001259.

12. Stosic R, Dunagan F, Palmer H, Fowler T, Adams I. Responsible self-medication: Perceived risks and benefits of over-the-counter analgesic use. Int J Pharm Pract. 2011;19(4):236-45. doi: 10.1111/j.2042-7174.2011.00097.x, PMID 21733011

13. Al-Worafi YA, Long C, Saeed M, Alkhoshaiban A. Perception of self-medication among university students in Saudi Arabia. Arch Pharma Pract. 2014;5(4):149. doi: 10.4103/2045-080X.142049.

14. UB G, Tadvi NA. Paracetamol toxicity: A review. J Contemp Med Dent. 2014

Article History: Received: 22-07-2021; Revised: 28-09-2021; Accepted: 02-11-2021.

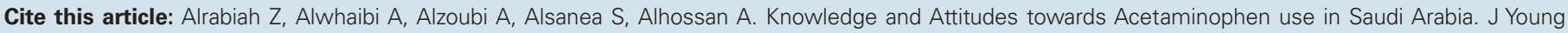
Pharm. 2021;13(4):423-8. 